\title{
Perception of colour scales used in thematic cartography by young people aged 15-17
}

\author{
Barbora Musilová \\ Student of Geomatics Programme \\ Faculty of Applied Sciences, University of West Bohemia in Pilsen \\ baramusilova@gmail.com
}

\begin{abstract}
There are many different types of datasets represented by maps in thematic cartography. It is possible to represent features and phenomenon referencing to area as well as to point. Furthermore, it is possible to represent qualitative data as well as quantitative data. There are many different ways to represent them. One of the most important and most used cartographic symbols of lettering is colour, resp. colour scales, which are chosen according to shown data. This article is focused on the perception of colour scales in relation to character of data. For experiment, a new questionnaire was created on the basis of colour scales classification. This questionnaire was posed to the students of years 1 and 2 of high school in order to find out how they perceive the colour scales. The study analyzes three main questions; whether students differentiate qualitative and quantitative datasets and corresponding colour scales, whether they prefer representing of features by context colours or by the colour they like more and whether they are familiar with principles of diverging colour scales. When processing it, the correlation between certain agents and the answers was established.
\end{abstract}

Keywords: thematic cartography, perception of colour scales

\section{Introduction}

One comes across a map, a scheme or a topological sketch every day. We need to understand GPS (Global Positioning System) navigation system while driving; we should be able to get to some places according to a transit scheme. Choropleth or other thematic maps are often used in newspapers to accompany an article and we should be able to read them correctly and easily. We have been learning these skills since childhood, when using maps during school lessons, to illustrate historical or geographical phenomena and help to learn more about the world and its relationships. The more one is pressed to use map, the more ability to read maps quickly and correctly he earns.

There are many different ways to show required phenomena on a map. We can choose from several cartographic methods depending on different characteristics of data (various methods are widely described in literature about making maps and cartography in general, e.g. (Brewer, 2005) or (Voženílek, 2004)). To feature the particular phenomenon, a map symbol is used which has specific visual variables (as colour, shape, position...)(Bertin, 1981) in conformity with shown data. The values of attribute that are used depend mostly on the cartographer. However, we should consider some facts, conventions and other aspects to be considered (as purpose of the map, available software, financial resources, or focus group and 
their cartographical literacy).

According to several experiments, it is easier to read a map when it is coloured (e.g., Brewer, 1997). People can differentiate area symbols better when colour codes are used than when there are used codes based on texture (see Philips, 1980). Moreover, colour maps generally attract more users than monochromatic maps do. The fact whether one likes the map or not, depends also on the harmony of used colours. The definition and characterization of colours harmony is proposed in the article "Colours harmony in cartography" (Christophe, 2011). There also exists a possibility to use the same colours on maps as those used on some famous paintings (see Cartwright, 2009).

Colour is one of cartographic symbols of expression; it carries information about represented phenomenon and, based on the characteristic of the phenomenon, proper colour is chosen. There exist some conventions of using particular colour scales for showing certain phenomena (e.g. the hypsometric scale to show heights, blue-red scale for temperature); the research aims to find out whether some of these habitual manners are understandable for common map users. A group of teenagers was chosen as a subject of the experiment (reasons for the choice and profile of the group are specified in the next chapter). For the experiment, three main classifications of colour scales were specified.

People associate some phenomena with particular colours unconsciously, like blue for issues related to water, green for nature, red for danger etc (Oravcová, 2009). In the experiment, some of these clearly associable phenomena were chosen as well as some phenomena with no specific colour to associate with to find out how strongly respondents sense the relation between feature and colour.

Like data can that be, generally speaking, split into two groups: qualitative and quantitative; the colours used to represent them can be split into the same two groups. The experiment was focused on determining whether respondents are able to perceive the difference between these two groups of data and assorted colour scales.

The last phenomenon examined in this experiment was the respondents' ability to work with divergent colour scales.

The first part of the article describes the methodology of experiment, the group of subjects, expected results and the procedure of research. The second (main) part deals with processing of received answers according to type of classification of colours, comparing them with expected results and checking possible dependences.

\section{The methodology of the experiment}

During schooldays, children make their first experience with cartographic works and their future attitude towards maps may be strongly influenced by the maps they work with in school. Books of maps and school atlases make a significant number of publications of cartographic publishers. Several comparisons of certain school atlases have been made; they were compared in relation to the aspect of development (e.g. Široká, 2009), also the content of maps used in schoolbooks and school atlases was analyzed (e.g. Šákrová, 2010). On the other hand, there is considerably less research on the perception of school maps by pupils than researches only comparing maps. That fact led to realization of this research. 


\section{a) The subject of the experiment}

While finding proper group of subjects, a few requirements were demanded. For experiment, 50-100 respondents were needed in approximately the same age with at least basic knowledge of understanding maps, but not more educated in this area than their peers. Due to the requirement of self-sufficiency, the age limit was set to 15 as the minimum age according to previous experiences with youth. Due to possibility of collective presentation and ability of fulfilling upper written requirements, four school classes were chosen.

There were 89 students from 1st and 2nd year of grammar school (gymnasium) distinguished by the type of grammar school; four-year and eight-year type, all of them with normal colour vision.

\begin{tabular}{|l|c|c|c|}
\hline $\begin{array}{l}\text { type of gymnasium } \\
\text { year of school }\end{array}$ & $\begin{array}{c}\text { eight-year } \\
\text { gymnasium }\end{array}$ & $\begin{array}{c}\text { four-year } \\
\text { gymnasium }\end{array}$ & total \\
\hline \hline $1^{\text {st }}$ year & 21 & 23 & 44 \\
\hline $2^{\text {nd }}$ year & 22 & 23 & 45 \\
\hline total & 43 & 46 & $\mathbf{8 9}$ \\
\hline
\end{tabular}

Table 1: Profile of group of the respondents

\section{b) Hypothesis}

As mentioned above, while forming hypotheses to be verified, three main characteristics of colour maps were reflected; showing quantitative and qualitative data, using contextual colours and understanding divergent colour scales.

Assumed results of the experiment were summed up in general hypotheses:

- only insignificant number of respondents choose different colour then the context one for showing phenomenon with common colour association

- respondents choose colour which they like most for showing phenomenon without clear colour association

- almost all respondents choose assorted colour scales for showing quantitative, resp. qualitative data

- more than half of respondents can work with divergent colour scale

For processing, general hypotheses with specific numbers for each question of the questionnaire were specified.

\subsection{Making of questionnaire}

The experiment was carried out as a questionnaire. Each question included a title of map (information about what should be represented on the map) and several (from 2 up to 6) colour variants of the map (see Fig. 1 or further Fig. 2). The Overview of all selective questions and used colour scales for each of them is represented further, in table 2. Respondents should choose the variant, which suited the title best. 17 selective questions and 7 additional questions were made to find out whether respondents understood the maps. The method of choropleth maps was mostly used. 
The Highlands Region was chosen as a reference area for the most of questions because of its regular shape. For some questions, the map of the Czech Republic was used as well. Data sets had been modified, so that the shown phenomenon would be mapped by particular colour scales more easily (for example; for the map showing the most common surname in the area, at least one surname was required to occur in two or more different areas).
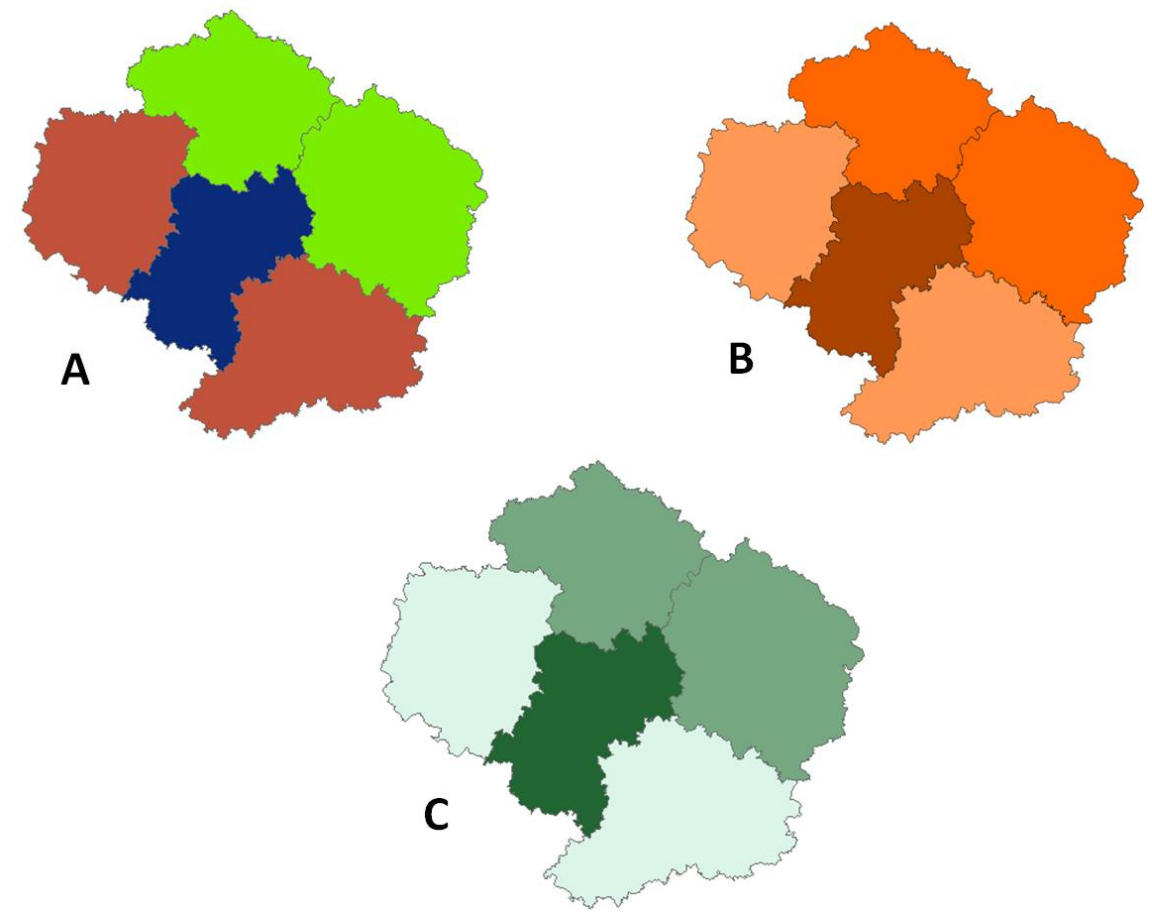

Figure 1: Monthly average wage in sub regions of the Highlands Region. Used colour scales: $\mathrm{A}$ - qualitative (improper) scale, B - quantitative (proper) scale, $\mathrm{C}$ - quantitative (proper) scale with colour context

\section{Procedure}

Considering the number of respondents, length of the questionnaire and possibility to present the stimuli to each class separately, the slide show was chosen as the best appropriate form of presentation.

Questions were put in such an order, that related questions were isolated, and every question was numbered. Colour variants were marked by letters. The slide show included 3 extra slides before the actual questions, which served as an introduction to the theory of colour scales, a slide with instructions for questionnaire and a slide with one question as an example.

Participants received a paper form as well, with numbers of questions and appropriate letters to check in chosen colour variant of map. Under every answer a free space was left for a brief substantiation.

The experiment took place in two consecutive days, each day with two classes. The presentation took approximately 45 minutes, the questionnaire itself 35 minutes. Participants were told to choose the colour variant which suits the particular title the best, without over- 
sophisticated thoughts. They were also asked to fill in their forms on their own, without any discussions with their schoolmates.

\section{Processing}

During the processing, completed forms were sorted by school classes. The answers were firstly processed for the whole group of participants (for all classes together) to get general results and then for two pairs of classes separated by age, by the day of the presentation or by the type of a grammar school in order to find eventual correlations.

Table 2 (resp. tables $2 \mathrm{a}$ and $2 \mathrm{~b}$ ) shows the relative number of votes for each colour variant of map. Every question is indicated by number and a shortened title of a map. Two deductions result from both the tables obviously; most of the tested students can differentiate quantitative and qualitative character of data and assign them an appropriate colour scheme. Also, when the prime context colour variant was available, students chose it more often than the alternative one.

For learning whether students understand divergent scales additional questions were mostly applied, and these are processed further in this chapter.

\begin{tabular}{|c|c|c|c|c|}
\hline \multirow[b]{2}{*}{$\begin{array}{l}\text { colour scale variant } \rightarrow \\
\text { question } \\
\downarrow\end{array}$} & \multirow[t]{2}{*}{ qualitative scale } & \multicolumn{3}{|c|}{ quantitative scale } \\
\hline & & 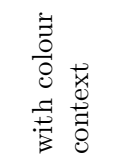 & 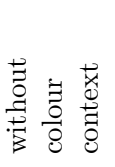 & 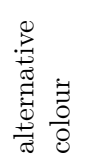 \\
\hline 1. male and female rate & & $80(>50)$ & 9 & - \\
\hline 3. the most common surname & 18 & - & 29 & 26 \\
\hline 5. soil usage & & 67 & 9 & 21 \\
\hline 10. results of traffic collisions & & 35 & - & \begin{tabular}{l|l}
8 & 34 \\
\end{tabular} \\
\hline 13. local elections & & $62(>80)$ & 8 & - \\
\hline
\end{tabular}

Table 2a. Results of selective questions - qualitative data [\%]

\begin{tabular}{|c|c|c|c|c|c|}
\hline \multirow[b]{2}{*}{$\begin{array}{l}\text { colour scale variant } \rightarrow \\
\text { question } \\
\downarrow\end{array}$} & \multicolumn{4}{|c|}{ qualitative scale } & \multirow[t]{2}{*}{ quantitative scale } \\
\hline & 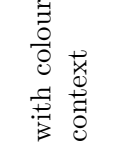 & 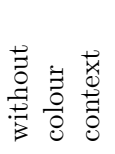 & 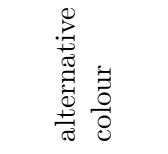 & 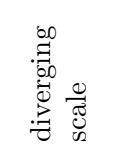 & \\
\hline 2. average wage & 49 & 29 & - & - & $22(<2)$ \\
\hline 6. density of suicides & $58(<10)$ & 16 & \begin{tabular}{l|l}
5 & $21(<10)$
\end{tabular} & & - \\
\hline 8. population growth & - & 66 & - & 11 & $23(<1)$ \\
\hline 16. forestation & $52(>60)$ & 2 & - & 5 & $39(<40)(\mathrm{cc})$ \\
\hline 19. density of open swimming pools & $83(>90)$ & 3 & 14 & - & - \\
\hline 23. population & - & 6 & 14 & $12(<5)$ & $6(<1)$ \\
\hline 24. mortality on roads & 74 & $10(<1)$ & 16 & - & - \\
\hline 27. recreation facilities & $28(>50)$ & 36 & $11(20)$ & - & $25(<5)$ \\
\hline 29. population growth & - & 63 & - & $16(>60)$ & $21(<1)$ \\
\hline 31. forestation & 75 & - & - & 25 & \\
\hline
\end{tabular}

Table 2b. Results of selective questions - quantitative data [\%]

The expected values are stated in the parentheses (where "<" resp. ">" means "less than" resp. "more than"). Sign "-" means that the scale described in the column was not created for the question. The coloured cells contain the most frequent answer. Some questions contain more variants of context colour, these are separated as "with colour context" and "alternative" 
(e.g., question with map of density of suicides contains three context variants: grey, red, and ruby).

Letters "cc" in question 16 mean qualitative (improper) scale with colour context.

\section{a) Results}

\section{Qualitative/quantitative data}

Ability of students to identify difference between representation of quantitative and qualitative data was tested by selective questions only.

Let us see the table 2 once more. Despite the fact that the suitable colour variant was the most frequently chosen in each question, the second one was almost every time the improper one (qualitative scale for quantitative data and contrariwise). Statistic test (t-test) proved that the improper colour variant is chosen by $20 \%$ of students. Table 3 illustrates a comparison of expected and actual numbers of students, who chose the improper colour variant.

\begin{tabular}{|c|c|c|c|c|c|c|c|c|c|c|c|c|}
\hline question & 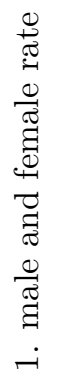 & 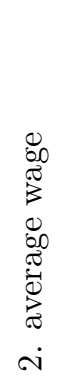 & 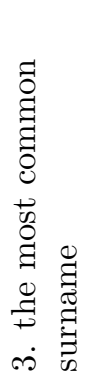 & 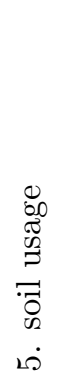 & 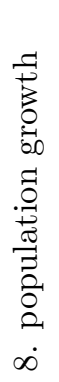 & 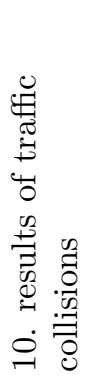 & 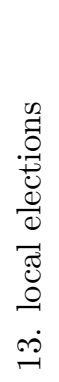 & 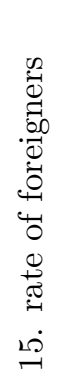 & 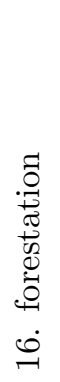 & 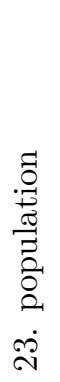 & 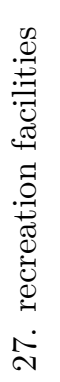 & 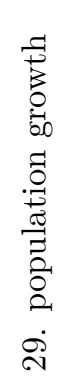 \\
\hline expected numbers & $<1$ & $<5$ & $<1$ & - & $<1$ & $<1$ & - & $<1$ & - & $<1$ & $<5$ & \\
\hline real numbers & 9 & 22 & 27 & 3 & 23 & 23 & 30 & 10 & 41 & 6 & 25 & 21 \\
\hline
\end{tabular}

Table 3: Comparing of expected and real number of respondents who chose improper colour variant [\%]

There appear some questions with strongly different results than $20 \%$. Questions 1 and 5 present qualitative data with strong colour context, but context colours are not used for showing with the quantitative colour scale. Students probably chose the appropriate colour scale because of the context colour, not thinking about qualitative or quantitative character. The influence of colour is obvious in question 16 (Fig. 2), where the context colour was used in qualitative and also quantitative version. The statistic test showed that the number of votes was congruent for both variants in that question.

If respondents chose the improper colour variant, they often explained their choice by saying that the chosen colours are nice, pretty, or well contrasting.

\section{Colour context}

We can clearly see in the table 2 , that in case that one of the colours variant of map was made with context colours, participants chose this one the most frequent. Moreover, when using qualitative and quantitative colour scales, both in context colours, they were chosen with the same frequency. In most cases, more than half of respondents chose the context colour variant or the alternative context colour variant. 


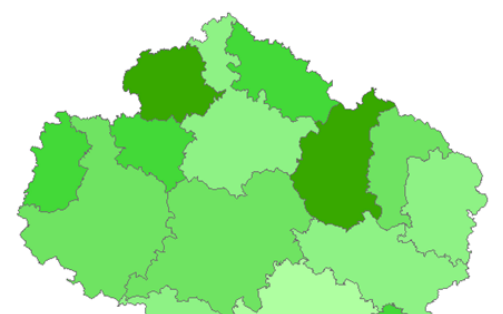

A
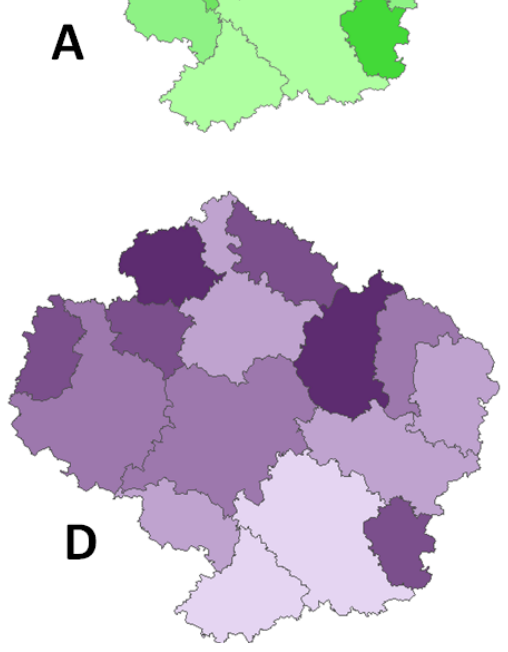
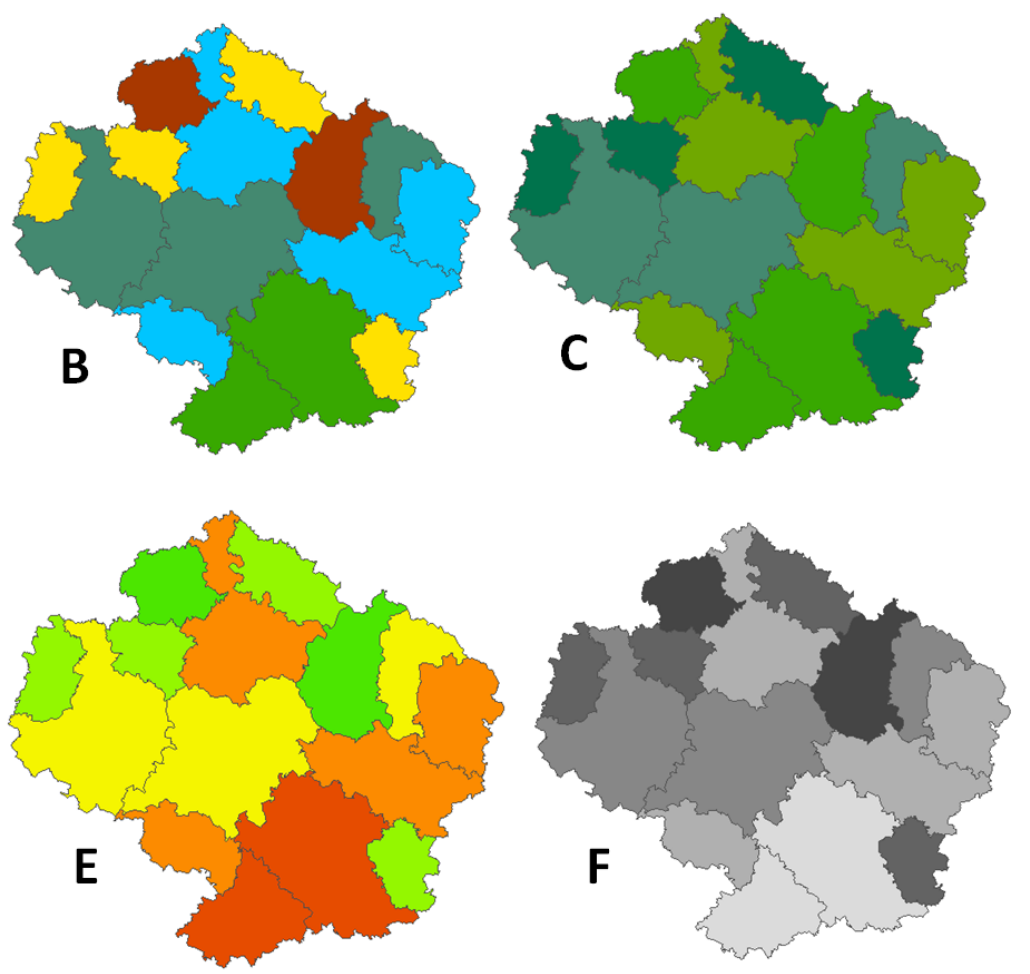

Figure 2: Forestation in sub regions of the Highlands Region. Used colour scales: A quantitative (suitable) context scale, $\mathrm{B}$ - qualitative (improper) scale, $\mathrm{C}$ - qualitative context scale, D - quantitative scale, E - quantitative diverging scale, F - grey scale

For detailed processing the t-test was applied. Table 4 shows the comparison of expected values and the values that I got.

\begin{tabular}{|c|c|c|c|c|c|c|c|c|c|c|c|c|}
\hline \multirow[t]{2}{*}{$\begin{array}{l}\text { question } \\
\rightarrow\end{array}$} & \multicolumn{2}{|c|}{$\begin{array}{l}\text { 1. male and } \\
\text { female rate }\end{array}$} & \multirow{2}{*}{$\begin{array}{l}2 . \\
\text { average } \\
\text { wage }\end{array}$} & \multicolumn{2}{|c|}{ 5. soil usage } & \multicolumn{3}{|c|}{ 6. number of suicides } & \multicolumn{2}{|c|}{$\begin{array}{l}\text { 10. results of } \\
\text { traffic collisions }\end{array}$} & \multirow[t]{2}{*}{$\begin{array}{l}\text { 13. local } \\
\text { elections }\end{array}$} & \multirow[t]{2}{*}{$\begin{array}{l}16 . \\
\text { forestation }\end{array}$} \\
\hline & prim. & alt. & & prim. & alt. & prim. & alt1. & alt2. & prim. & alt. & & \\
\hline $\begin{array}{l}\text { expected } \\
\text { values }\end{array}$ & $>50$ & $<10$ & - & - & 20 & 10 & 10 & - & - & - & $>80$ & $>60$ \\
\hline get values & 80 & 11 & 49 & 21 & 67 & 58 & 21 & 5 & 35 & 8 & 62 & 91 \\
\hline \multirow[t]{2}{*}{$\begin{array}{l}\text { question } \\
\rightarrow\end{array}$} & \multicolumn{2}{|c|}{$\begin{array}{l}\text { 19. open } \\
\text { swimming } \\
\text { pools }\end{array}$} & \multicolumn{2}{|c|}{$\begin{array}{l}\text { 24. mortality on } \\
\text { roads }\end{array}$} & \multicolumn{2}{|c|}{$\begin{array}{l}27 . \\
\text { recreation } \\
\text { facilities }\end{array}$} & & & & & & \\
\hline & prim. & alt. & prim. & alt. & prim. & alt. & & & & & & \\
\hline $\begin{array}{l}\text { expected } \\
\text { values }\end{array}$ & $>90$ & - & - & - & $>70$ & 20 & & & & & & \\
\hline get values & 84 & 14 & 74 & 16 & 28 & 11 & & & & & & \\
\hline
\end{tabular}

Table 4: Comparison of expected and received number of answers for colour context map variants $[\%]$

When more associative variants for map occur, they are separated as prim. (primary) and alt. (alternative) (e.g. mortality on roads was mapped by grey, red and blue quantitative scales; grey represents primary context variant, red represents alternative context variant, and blue has no colour association, therefore it does not occur in the table). 


\section{Sequential/divergent scale}

In the questionnaire, a few selective questions aimed to find out, whether students would assign divergent colour schemes to data, which could be symbolized by diverging scale. A triplet of colour variants of map showing population growth was used in two questions; in the first one only with title, in the second one with a title and a legend referencing to zerocrossing data. In both questions, more than $60 \%$ of students chose the sequential scale as more suitable, while the divergent scale was chosen by $11 \%$ of respondents in the question only with title, and by $16 \%$ in the question with a legend. Statistical test did not approve difference between these two results.

The questionnaire also included 3 additional questions to find out if students can work with the diverging scale when used on a map. In the first one, a forestation was mapped by orangeyellow-lime green diverging scale. Students should choose the region with the biggest rate of forestation. As expected, most of them chose the region coloured by saturated green $(77 \%)$, nevertheless almost one fifth of them chose an orange coloured region.

Another question aimed to recognize ability of students to identify a border on a scale, which represents breaking value (usually zero or mean). Diverging colour scale was drawn with 5 steps; 3 of them were red, 2 of them were blue. Number values on both ends of scale indicated its range (negative number on left end, positive number on right end). Respondents should assign values to borders of colour steps. It was expected that at least $20 \%$ of them would have assigned the value of zero to the border between light blue and light red, however only $5 \%$ of students assigned the zero to the border. This result could be caused by the fact that students expected sections with the same length thus they divided the interval that way.

In last additional question, a map of average temperature was made in 3 colour variants; one with symmetric divergent scale, one with asymmetric divergent scale (both divergent scales were blue-beige-red) and one with yellow-red sequential scale. Students should have assigned temperature interval to each of these variants. It was observed whether the interval crosses zero. For variant with the symmetric scale $87 \%$ of students wrote down an interval crossing zero, $60 \%$ of respondents wrote it down for the asymmetric variant and 9 _ of respondents for the sequential variant $9 \%$ of respondents.

\section{Correlation}

While filling the questionnaire in, there surely occurred some agents which influenced respondents' answers. Some of them, as specific perception of colours by each person, are not detectable, while some external agents could be found. The experiment took place in two days with different weather (cloudy the first day and sunny the second day); on each day the questionnaire was presented to a class of students of 1st year and a class of students of the 2nd year of study. From these classes one class was from eight-year gymnasium and one from four-year gymnasium, so all agents could have been tested without chance of mistaking them. For processing, chi-squared test of independence and paired t-test were used.

Correlation between answer and type of study (eight-year or four-year gymnasium) was located in questions about quantitative and qualitative data and their representation. There are shown relative numbers of students who chose improper colour variant in table 5 . Statistical test proves a significant difference in answers between the two varying types of study. Thus students of the four-year gymnasium generally choose improper colour variant more often 


\begin{tabular}{|c|c|c|c|c|c|c|c|c|c|c|c|c|}
\hline $\begin{array}{l}\text { question } \rightarrow \\
\text { students of: }\end{array}$ & 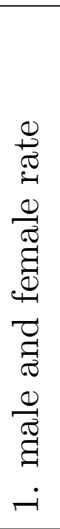 & 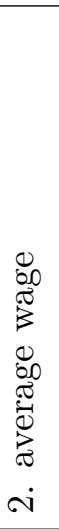 & 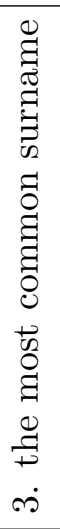 & $\begin{array}{l}0 \\
80 \\
6 \\
0 \\
3 \\
7 \\
7 \\
0 \\
10 \\
10\end{array}$ & 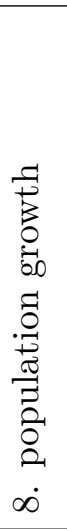 & 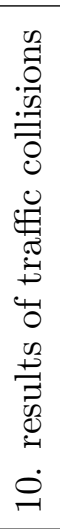 & 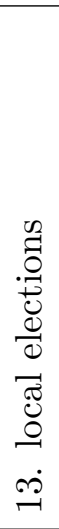 & 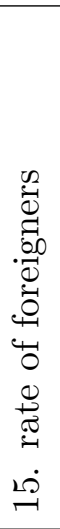 & 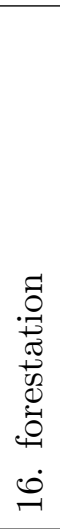 & 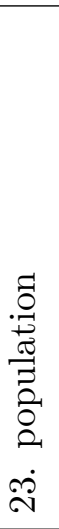 & 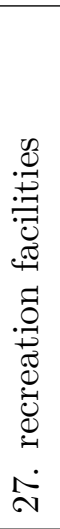 & 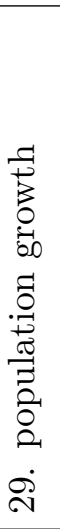 \\
\hline $\begin{array}{l}\text { eight-year } \\
\text { gymnasium }\end{array}$ & 2 & 7 & 46 & 0 & 16 & 21 & 26 & 7 & 37 & 5 & 27 & 14 \\
\hline $\begin{array}{l}\text { four-year } \\
\text { gymnasium }\end{array}$ & 15 & 37 & 43 & 7 & 28 & 26 & 35 & 13 & 44 & 7 & 23 & 27 \\
\hline
\end{tabular}

Table 5: Numbers of students who chose improper colour variant according to the type of study $[\%]$

than students of the eight-year gymnasium.

Results of one of the questions also indicate correlation between age (respectively year of school) and perception of green colour as context colour of money. While $59 \%$ of students of 2nd year of study chose green sequential scale for showing monthly average wage, the green variant was chosen only by $45 \%$ of younger students. The answers by the undergraduate students, who chose green by $75 \%$, confirmed theory that one earns association of greenmoney.

During the processing, correlations were also detected between weather and answers for some questions. The reason mostly consists in the way the questionnaire was presented, when bright colours stayed expressive on slide show on both days, while less saturated colours lost their hue on sunny day.

\section{b) Comments of Results}

At the beginning of the experiment general hypotheses were determined in order to be compared with the observed results. In spite of the fact that the tests of independence proved correlation between certain agents and answers in some questions, outcomes of these questions were included in the processing. That could be done because of the equal distribution of these aspects.

H1: Only insignificant number of respondents chooses different colour than the context one for showing phenomenon with common colour association.

This hypothesis was dismissed. When the mapped phenomenon had colour context, at least $10 \%$ of students chose a different colour variant.

H2: Respondents choose colour which they like the most for showing phenomenon without clear colour association. 
This hypothesis has not been proved. Students often gave reason for their choice by other points of view (colour contrast, suitability of sequential scale for rising phenomenon). From $14 \%$ to $52 \%$ of respondents who wrote the reason for choosing that specific answer advanced their liking for the colours.

H3: Almost all respondents choose assorted colour scales for showing quantitative, resp. qualitative data.

This hypothesis was accepted. Suitable colour scale was preferred by almost $80 \%$ of respondents. The choice also depended on the type of study, when students from 8-year gymnasium choose the suitable colour variant relatively more often than students of 4-year gymnasium.

H4: More than half of respondents can work with divergent colour scale.

This hypothesis was neither accepted nor dismissed. More than $75 \%$ of students could correctly compare colours on diverging scale (while on converging scale $85 \%$ of them qualify the appropriate relation). However, only $5 \%$ were able to correctly assign breaking value on diverging colour scale with different long intervals.

\section{Conclusion}

The experiment aimed to determine whether the colour scales commonly used on thematic maps are understandable for students of high school. The research analyzed, whether they discern differences between certain characteristics of data (as qualitative and quantitative data), whether they can assign a corresponding colour scale to the data and whether they can work with maps with various colour scales.

Variances between colour scales as well as between different characteristics of data were expected to be easily found by the majority of students. The processing of research shows that most of the students can clearly differentiate qualitative and quantitative data and they can assign an appropriate colour scale to them. In addition, the assignment of appropriate colour scale is easier for the students of eight-year gymnasium than for the students of four-year gymnasium. The ability of intuitive differentiating qualitative and quantitative data could cause eventual problems with using rainbow scale to present ordered data, as described in (Borland, 2007).

It was also detected that the eventual colour context of the scale influences the chosen variant strongly. In general, the used colour and its colour context affect the perception of the mapped feature significantly. This illustrates the frequent misinterpretation of hypsometric scale, whose tints students confuse with information about vegetation or climate (Patterson, 2011).

Understanding of diverging colour scales was neither approved nor dismissed. Propriety and usability of diverging colour scales are discussed in several studies with different results. Lewandowsky suggests using bipolar scales with caution (Lewandowsky, 1993); also Ware advises rather to use scale increasing monotonically in luminance to obtain accurate reading (Ware, 1988). On the other hand, Moreland prefers the diverging scales for their logical structure (Moreland, 2009) and MacEachren mentions a study that proves the perception of order in the blue-red diverging scale (MacEachren, 2004). This paper confirms the necessity 
of proper consideration to use the diverging scale, since it causes a misleading rather than the converging scale, but also indicates that most of students are able to understand and correctly compare ending colours.

The experiment offers several possibilities for other research. Differences between answers of students of gymnasiums and students of other high schools (e.g. technical colleges) could be determined. The research can be extended to get generalized information about the perception of colour scales by pupils. These results could be compared with maps used in school atlases and other schoolbooks. The questionnaire could also be submitted to other students of 1st and 2nd year of gymnasium and compare results of current and previous research.

\section{References}

[1] BERTIN, Jacques. Graphics and graphic information-processing. Berlin: W. de Gruyter, 1981. ISBN 3110088681.

[2] BREWER, Cynthia A. Designing better maps: a guide for GIS users. California: ESRI Press, 2005. ISBN I-58948-089-9.

[3] BREWER, Cynthia A., HERMANN, Douglas, MACEACHREN, Alan M., PICKLE Linda W. Mapping Mortality: Evaluating Color Schemes for Choropleth Maps. Annals of the Association of American Geographers. 1997, vol.87, no.3, p. 411-438.

[4] BORLAND, David, TAYLOR, Russel M. Rainbow Color Map (Still) Considered Harmful. Computer Graphics and Applications, IEEE. 2007, vol.27, no.2, p.14-17. on-line available at: http://www.jwave.vt.edu/ \{\}rkriz/Projects/create_color_table/color_ 07.pdf

[5] CARTWRIGHTER, William, GARTNER, Georg, LEHN, Antje. Cartography and Art. Berlin Heidelberg: Springer, 2009. ISBN 978-3-540-68567-8.

[6] CHRISTOPHE S., ZANIN C., ROUSSAFFA H. Colours Harmony in Cartography. Proceedings of the 25th International Cartographic Conference [online]. Paris: 2011. ID: CO084. ISBN: 978-1-907075-05-6. on-line available at:

http://icaci.org/files/documents/ICC_proceedings/ICC2011/0ral\%

20Presentations\%20PDF/B1-Graphical\%20Semiology , \%20visual\%20variables/

C0-084.pdf

[7] LEWANDOWSKY, Stephan, HERRMANN, Douglas J., BEHRENS, John T., LI, ShuChen, PICKLE, Linda, JOBE, Jared B. Perception of Clusters in Statistical Maps. Applied Cognitive Psychology. 1993, vol. 7, is. 6, p. 533-551.

[8] MACEACHREN, Alan M. How Maps Work: Representation, Visualization, and Design. New York: Guilford Press, 2004. ISBN 1-57230-040-X.

[9] MORELAND, Kenneth. Diverging Color Maps for Scienti[FB01?]c Visualization (Expanded). not-expanded version published in: Proceedings of the 5th International Symposium on Visual Computing. 2009. on-line available at:

http://www.sandia.gov/ \{\}kmorel/documents/ColorMaps/ 
[10] ORAVCOVÁ, Jitka. Colour Importance in Visualization of Information. Journal of Technology and Information Education [online]. 2009, vol.1, no.2, p.24-32. ISSN 1803-537X. on-line available at: http://www.jtie.upol.cz/clanky_2_2009/oravcova.pdf (in Slovak)

[11] PATTERSON, Tom, JENnY, Bernhard. The Development and Rationale of Crossblended Hypsometric Tints. Cartographic Perspectives. 2011, no. 69. p.31-46.

[12] PHILLIPS, Rachard J., NOYES, Liza. A comparison of color and visual texture as codes for use as area symbols on thematic maps. Ergonomics [online]. Taylor \& Francis, 1980, vol.23, no.12, p.1117-1128. ISSN 0014-0139. on-line available at:

http://www.richardphillips.org.uk/maps/map1980.pdf

[13] ŠÁKROVÁ, Michaela. Analysis of Contents of Teaching Maps of Czech Geography Textbooks and School Atlases. Prague: Charles University, Faculty of Science, 2010. Bachelor thesis. on-line available at:

https://is.cuni.cz/webapps/UKSESSIONC6ACFFBAF6B62ADFCFF0F049F7B7B649/zzp/ download/130000895/?back_id=3 (in Czech)

[14] ŠIROKÁ, Silvie. The Evolution of the School Geographic Atlases, Their Conceptions, Themes and Scales. Brno: Masaryk Universtiy, Faculty of Education, 2009. Bachelor thesis. on-line available at: http://is.muni.cz/th/209487/pedf_b/BAKALARSKA_PRACE. pdf (in Czech)

[15] VOŽENÍLEK, Vít. Aplikovaná kartografie I. - tematické mapy. 2. vyd. Olomouc: Palacký University, 2004. ISBN 80-244-0270-X. (in Czech)

[16] WARE, Colin. Color Sequences for Univariate Maps: Theory, Experiments, and Principles. IEEE Computer Graphics and Applications. 1988, vol. 8, no. 5, p.41-49. on-line available at: http://ccom.unh.edu/sites/default/files/publications/Ware_1988_ CGA_Color_sequences_univariate_maps.pdf 